\title{
Expression of TRAIL and TRAIL receptors in normal and malignant tissues
}

\author{
Raymond A DANIELS ${ }^{1}$, Helen TURLEY ${ }^{2}$, Fiona C KIMBERLEY ${ }^{3}$, Xue Song LIU ${ }^{4}$, Juthathip MONGKOLSAPAYA ${ }^{3}$, \\ Paul CH'EN ${ }^{1}$, Xiao Ning XU ${ }^{1}$, Boquan JIN ${ }^{4}$, Francesco PEZZELLA², Gavin R SCREATON ${ }^{3, *}$ \\ ${ }^{1}$ Human Immunology Unit, Weatherall Institute of Molecular Medicine, University of Oxford, John Radcliffe Hospital, Oxford \\ OX3 9DS, UK \\ ${ }^{2}$ Nuffield Department of Clinical Laboratory Sciences, University of Oxford, John Radcliffe Hospital, Oxford OX3 9DS, UK. \\ ${ }^{3}$ Hammersmith Hospital, Du Cane Road, London W12 0NN, UK. \\ ${ }^{4}$ Department of Immunology, Fourth Military Medical University, Xi'an 710032, China.
}

\begin{abstract}
TRAIL, tumor necrosis factor-related apoptosis-inducing ligand, is a member of the TNF family of proteins. Tumour cells were initially found to have increased sensitivity to TRAIL compared with normal cells, raising hopes that TRAIL would prove useful as an anti-tumor agent. The production of reliable monoclonal antibodies against TRAIL and its receptors that can stain fixed specimens will allow a thorough analysis of their expression on normal and malignant tissues. Here we report the generation of monoclonal antibodies against TRAIL and its four membrane-bound receptors (TR1-4), which have been used to stain a range of normal and malignant cells, as routinely fixed specimens. Low levels of TRAIL expression were found to be limited mostly to smooth muscle in lung and spleen as well as glial cells in the cerebellum and follicular cells in the thyroid. Expression of the TRAIL decoy receptors (TR3 and 4) was not as widespread as indicated by Northern blotting, suggesting that they may be less important for the control of TRAIL cytotoxicity than previously thought. TR1 and TR2 expression increases significantly in a number of malignant tissues, but in some common malignancies their expression was low, or patchy, which may limit the therapeutic role of TRAIL. Taken together, we have a panel of monoclonal antibodies that will allow a better assessment of the normal role of TRAIL and allow assessment of biopsy material, possibly allowing the identification of tumors that may be amenable to TRAIL therapy.
\end{abstract}

Keywords: apoptosis, immunohistochemistry, monoclonal antibodies, tumor markers.

\section{INTRODUCTION}

TRAIL is a type II transmembrane protein and a member of the TNF family $[1,2]$. Preliminary Northern blotting analyses showed that TRAIL is expressed on a wide range of tissues [2]. TRAIL activates apoptosis through the death receptors TR1 (TRAILR-1, DR4) and TR2 (TRAILR-2, DR5, TRICK2, KILLER), which are members of the TNFR superfamily [3-6]. TRAIL also binds two other membrane bound receptors, TR3 and TR4, which bear substantial sequence homology in the extracellular domain to TR1 and TR2. TR3 (TRAILR-3, DcR1, LIT, TRID) is a GPI linked protein, while TR4 (TRAILR-4, TRUNDD,

*Correspondence: Gavin R SCREATON

Tel: 44-1865-222442; Fax: 44-1865-222470;

E-mail: g.screaton@imperial.ac.uk.
DcR2) has an incomplete death domain; both do not trigger apoptosis [6-9]. Thus, it was proposed that these receptors might serve as 'decoys', competing for TRAIL's binding with the pro-apoptotic molecules, TR1 and TR2. Increased expression of these so-called decoys on normal cells was thought to be the major factor responsible for protecting from TRAIL-induced apoptosis. Besides the above 4 receptors, TRAIL also has a fifth receptor, osteoprotegerin (OPG), which is secreted as a soluble dimer $[10,11]$ and performs an important decoy function in osteoclastogenesis through binding OPGL/RANKL/ TRANCE. However, studies on TRAIL knockout mice questioned its role as a TRAIL regulator $[12,13]$.

In vitro, TRAIL was shown to be able to induce apoptosis in a variety of tumor cells, raising hopes that TRAIL may have therapeutic potential as an anti-cancer agent $[1,2]$. It has also been shown that soluble TRAIL and monoclonal 
antibodies against TR1 and TR2 exert potent anti-tumor activity in vivo without systemic toxicity [14-16]. Despite the widespread interest in TRAIL and its receptors, there has been no systematic survey of their expression in normal and malignant tissues. Such studies have been limited by the lack of monoclonal antibodies reactive on paraffin sections. In this report we describe a panel of such reagents.

\section{MATERIALS AND METHODS}

\section{Monoclonalantibodies}

Recombinant proteins were prepared as previously described $[6$, 17]. Monoclonal antibodies were raised in $\mathrm{BALB} / \mathrm{c}$ mice against Fcfusion proteins of TRAIL and TR1-4. Initial characterization was performed on unfixed 293T cells (human embryonic kidney cells), transiently expressing TR1-4 and TRAIL. Cells were transfected using calcium phosphate precipitation, harvested after $24 \mathrm{~h}$ and then stained with monoclonal antibody (mAb) at a concentration of $5 \mu \mathrm{g}$ / $\mathrm{ml}$ in $\mathrm{PBS} / 5 \% \mathrm{FCS}$ for $30 \mathrm{~min}$ at $4^{\circ} \mathrm{C}$. Following washing they were then counterstained with rabbit anti-mouse $\mathrm{PE}$ at a $1 / 100$ dilution (Dako). Cells were analysed on a FACScan (Becton Dickinson). Specificity was confirmed using cells transfected with an irrelevant cDNA expression vector, and each of the TRAIL receptor antibodies was tested for cross-reactivity against the other receptors.

Specificity of the TRAIL monoclonal antibody was also shown by staining soluble TRAIL bound to Jurkat cells, which express high levels of endogenous TR2. Cells were counted and $1 \times 10^{5}$ cells were incubated in RPMI at $37^{\circ} \mathrm{C}$ for $1 \mathrm{~h}$ with $400 \mathrm{ng}$ of recombinant soluble TRAIL-Flag (Alexis). The cells were then washed twice and incubated for $1 \mathrm{~h}$ with $5 \mu \mathrm{g} / \mathrm{ml}$ of either the TRAIL monoclonal antibody, or monoclonal anti-Flag (Sigma) as a positive control. The cells were then washed again and stained for $1 \mathrm{~h}$ with anti-mouseIgG-PE (Dako) at a concentration of $1 / 100$.

Western blot analysis was carried out on cell lysate from transfected 293T cells. The membrane (Hybond-C, Amersham Biosciences) was blocked with PBS containing 5\% milk, before applying antibody and washed in PBS containing 0.1\% Tween-20. Blots were then incubated with a HRP-conjugated rabbit anti-mouse antibody at a 1/1000 dilution (DAKO), and developed using ECL reagent (Amersham Biosciences).

\section{Immunocytochemical staining}

Initial characterisation of the antibodies on fixed cells was performed using 293T cells transfected with control or cDNA expression vectors for TRAIL or its four receptors. Cells were cytocentrifuged onto microscopic slides and fixed in $100 \%$ acetone. Alternatively, cells were fixed in $10 \%$ buffered formalin, pelleted and embedded in paraffin; $4 \mu \mathrm{m}$ sections were cut onto silane-coated slides.

Both acetone-fixed and paraffin wax embedded sections were incubated for $30 \mathrm{~min}$ with monoclonal antibodies, followed by antimouse HRP conjugate (DAKO). The peroxidase reaction was developed using diaminobenzidine and slides were washed and mounted in aqueous mount (Apathy's, BDH). Tissues were obtained from the Cellular Pathology Department at the John Radcliffe Hospital. Formalin fixed sections and paraffin wax embedded tissues were cut and immunostaining was carried out according a method decribed previously [18]. Sections were stained without pretreatment for antigen retrieval. Endogenous peroxidase activity was blocked with
$0.3 \%$ hydrogen peroxide in methanol for $30 \mathrm{~min}$ and rinsed in PBS/ azide prior to staining. Staining intensity was assessed for both tissue and cellular distribution and a semi-quantitative system was used: - negative; \pm equivocal; + weak; ++ moderate; +++ strong and ++++ very strong staining.

\section{Functional assays}

Apoptosis was examined using Annexin-V staining of Jurkat cells expressing high levels of endogenous DR5. Cells at a concentration of $5 \times 10^{5}$ cells per well of a 96-well plate were treated with $100 \mathrm{ng}$ of recombinant soluble TRAIL-Flag (Alexis), crosslinked with monoclonal anti-Flag (Sigma) at $5 \mu \mathrm{g} / \mathrm{ml}$ and incubated overnight. The cells were then stained with annexin-V-FITC $(5 \mu \mathrm{l} /$ well of cells in annexinV buffer: $140 \mathrm{mM} \mathrm{NaCl}, 10 \mathrm{mM}$ Hepes/NaOH pH7.4 and $5 \mathrm{mM}$ $\mathrm{CaCl}_{2}$ ) the following day and analysed by flow cytometry. Percentage apoptosis was calculated according to the percentage annexin- $\mathrm{V}$ positive, using propidium iodide (PI) to gate out necrotic cells.

\section{RESULTS}

\section{Characterization of antibodies}

A panel of newly generated monoclonal antibodies against TR1-4 and TRAIL were characterised using FACS staining of 293T cells transfected with the appropriate cDNA (Fig. 1). Due to the substantial sequence homology between TRAIL receptors cross-reactivity was checked on all four receptors (data not shown). Specific mAbs against TRAIL, TR1, TR2 and TR4 were obtained (Fig. 1A). No specific $m A b$ against TR3 was found, but one $\mathrm{mAb}$ (anti-TR3/4) cross-reacts with both TR3 and 4 and can be used as a reagent to assess combined decoy receptor expression (Fig. 1B). A number of lymphocyte cell lines were stained with the antibodies and a representative staining of BJAB (a B cell line), which expresses both TR1 and TR2, is shown (Fig. 1C). The Jurkat T cell line was found to express TR2 and TR3, while another B cell line, Namalwa, expresses TR2 and some TR1 and TR3 (data not shown).

Antibodies to TR1-4 were positve on Western blots of lysates from 293T cells transfected with the corresponding cDNA expression vectors (Fig. 1D). The anti-TRAIL $\mathrm{mAb}$ tested negative on cell lysates denatured on a Western blot, but was able to recognize soluble TRAIL bound to Jurkat cells (Fig. 1E). This demonstrates its ability to bind native TRAIL without occluding the receptor-binding surface.

\section{Functional characterization}

Next we examined whether the monoclonal antibodies against TRAIL, and TR2 were active in functional assays. First we tested whether the antibody against TR2 could stimulate apoptosis when added to Jurkat cells, which express high levels of TR2. Interestingly, when added alone they did not kill the cells but were able to block apoptosis when TRAIL was added (Fig. 2A). However, when the 
A
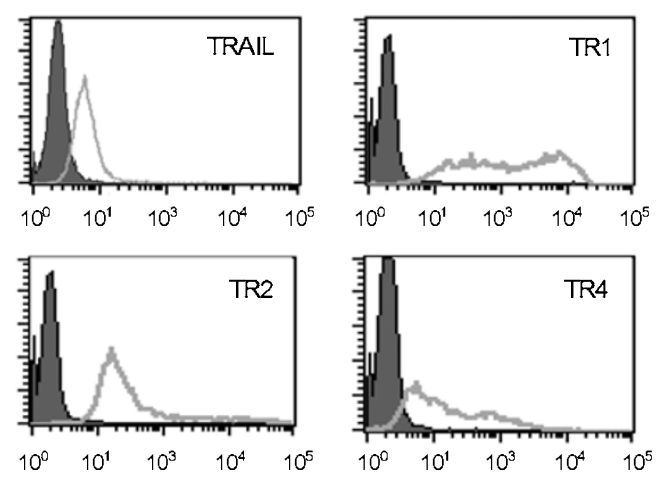

B

anti-TR3/4

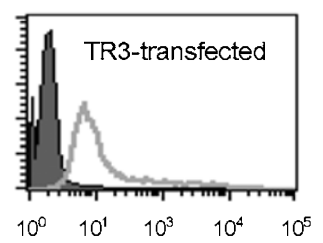

C

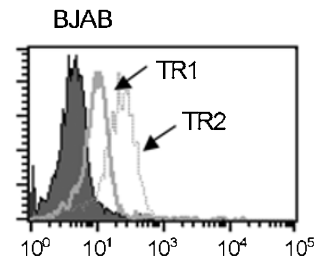

$\mathrm{E}$

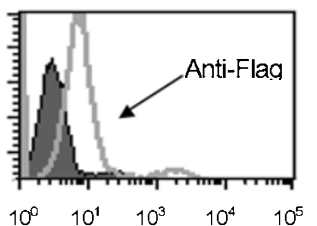

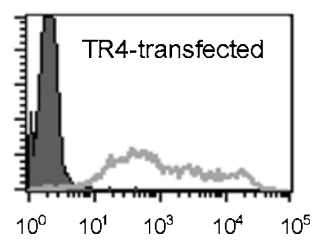

D

TR1 TR2 TR3 TR4
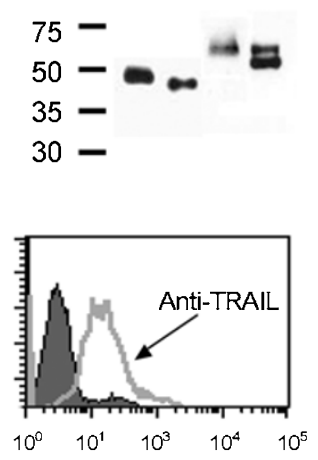

Fig. 1 FACS staining and Western blotting of TRAIL and the TRAIL Receptors. 293T cells: (A) Transfected with TRAIL, TR1, TR2, TR4 and stained with the corresponding mAb. (B) TR3 and TR4 transfected and stained with the cross-reacting mAb TR3/4. (C) The B lymphocyte cell line BJAB stained with anti-TR1 and TR2. (D) Western blot of cell lysates from 293T transfectants stained with respective antibodies. $293 \mathrm{~T}$ cells were transfected with GFP-tagged $\Delta$ cytoplasmic domain (CD) expression constructs. The predicted protein sizes for TR1-4-GFP $\Delta C D$ are $47,44,50$ and $46 \mathrm{kD}$, respectively. However, the apparent molecular weight for TR3 is slightly higher than this, due to a high degree of glycosylation; it has 5 potential N-linked glycosylation sites and a number of possible Olinked sites. (E) FACS analysis of soluble TRAIL bound to Jurkat cells. Jurkat cells were incubated with soluble TRAIL-Flag (Alexis) and stained for binding using either monoclonal anti-Flag (as a positive control) or monoclonal anti-TRAIL. Background, in grey, represents Jurkat cells stained with soluble TRAIL and anti-ms-PE.

A

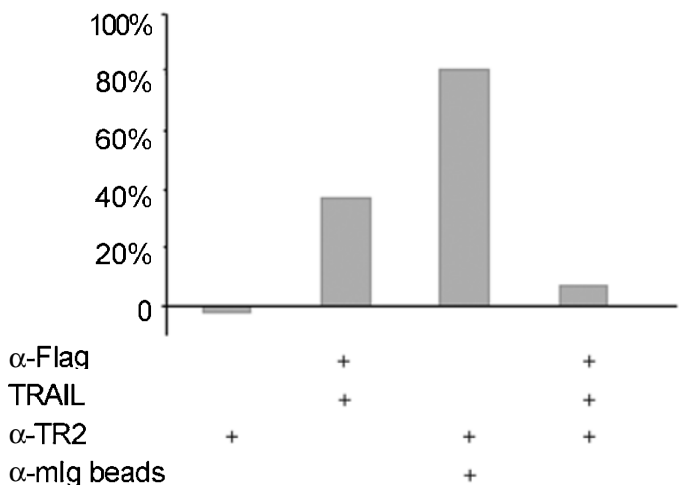

B

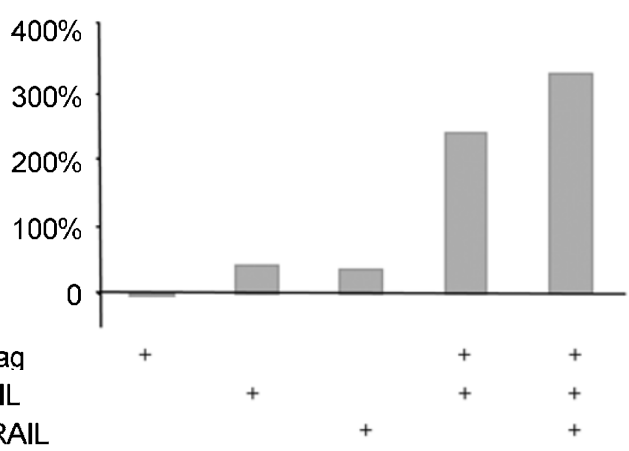

Fig. 2 Functional assays to assess Monoclonal antibody activity. Annexin-V staining was used to measure apoptosis. (A) Effect of anti-TR2 either alone, or cross-linked with dynabeads coated with goat anti-mouse IgG, on killing of Jurkat cells. (B) Effect of antiTRAIL on TRAIL induced apoptosis of Jurkat cells. This data is representative of three or more experiments.

antibody was cross-linked using beads coated with $\mathrm{mAb}$ specific for mouse $\operatorname{IgG~Fc}$, they were able to potently induce apoptosis. The antibody against TRAIL did not block TRAIL-induced apoptosis, further confirming that this is not an antagonistic antibody (Fig. 2B).

\section{Normal tissue distribution}

To test antibody reactivity on fixed cells, the antibodies were first applied to acetone- (data not shown) or formalin-fixed sections of transfected 293T cells. Analysis of these samples showed strong to moderate surface and cytoplasmic labeling of the antibodies (Fig. 3A-E). However, 293T cells transfected with either empty vector, or stained with isotype-matched anti-IgG, were negative (data not shown).

Next we stained paraffin embedded sections from a panel of normal tissues. The results are summarized in Tab. 1. TRAIL expression was more restricted than we had expected from Northern blot analyses [2]. Low levels of anti-TRAIL staining could be detected on glial cells in 
Tab. 1 The expression of TRAIL and receptors in normal tissue.

\begin{tabular}{|c|c|c|c|c|c|}
\hline Tissue & Number & TRAIL & TRAIL-R1 & TRAIL-R2 & TRAIL-R3/4 \\
\hline Adrenal & 2 & - & ++ & ++ & + \\
\hline Breast & 6 & - & + & + & - \\
\hline Cerebellum & 6 & ++ & +++ & ++++ & + \\
\hline Colon & 6 & - & ++ & ++ & \pm \\
\hline Duodenum & 6 & - & + & + & - \\
\hline Kidney & 4 & - & ++ & ++ & - \\
\hline Liver & 7 & - & ++++ & ++++ & - \\
\hline Lung & 6 & + & ++ & +++ & - \\
\hline Lymph node & 7 & - & + & + & \pm \\
\hline Myometrium & 2 & + & ++ & +++ & - \\
\hline Pancreas & 6 & \pm & + & ++ & - \\
\hline Placenta & 6 & \pm & \pm & \pm & - \\
\hline Prostate & 6 & + & + & ++ & \pm \\
\hline Small gut & 6 & - & \pm & ++ & + \\
\hline Spine & 6 & + & +++ & +++ & + \\
\hline Spleen & 6 & \pm & +++ & +++ & - \\
\hline Stomach & 6 & - & ++ & ++ & + \\
\hline Testis & 6 & - & + & ++ & - \\
\hline Thymus & 6 & - & ++ & ++ & - \\
\hline Thyroid & 6 & ++ & ++++ & +++ & ++ \\
\hline Tonsil & 6 & - & +++ & +++ & \pm \\
\hline
\end{tabular}

Staining intensity was assessed for both tissue and cellular distribution. A semi-quantitative system was used: - negative; \pm equivocal; + weak; ++ moderate; +++ strong and ++++ very strong staining. The column designated "Number" gives the number of samples examined for each tissue type.

the white matter of the cerebellum (Fig. 3E) and acini in the pancreas (Fig. 3G). There was also a high level of expression on follicular cells of the thyroid gland (Fig. $3 \mathrm{H})$ where it has already been suggested to play a role in normal apoptotic processes $[19,20]$. There was little staining with anti-TR4 and the cross-reactive anti-TR3/4. Weak staining was detected on glial cells in the cerebellum and spinal cord, and a few scattered cells in the tonsil and intestinal stroma. Moderate staining of follicular cells was observed in the thyroid gland (data not shown).

Anti-TR1 and TR2 stained most of the tissues strongly. In connective tissue and the stroma of all tissues, a variable proportion of fibroblasts and other cells were stained. There was consistent staining of smooth muscle in all the tissues with particularly strong staining around blood vessels in many tissues such as spinal cord (Fig. 3L). Staining was particularly strong on neuronal tissue in the cerebellum (Fig. 3I) and on hepatocytes (Fig. 3J). Few epithelial cells were positively stained in the stomach, duodenum and colon (Fig. 3K), a finding consistent with what had been reported in another study [21]. Anti-TR1 and TR2 also stained cells strongly in the basal layers of the glandular epithelium and there was staining of lymphoid cells in the spleen and tonsil. Interestingly, only a few lymphocytes in the germinal centers were positive, whereas most cells in the marginal zones around germinal centers in the tonsil were strongly stained (Fig. 3M).

\section{Tumor staining results}

Next we examined a panel of common tumors (Tab. 2): breast $(n=10)$, lung $(n=12)$, colon $(n=10)$, primary and metastatic melanoma $(n=13)$ and B-cell lymphomas $(n=12)$. No TRAIL was detected on any of the tumor cells. Weak staining for decoy receptors was detected in 5/13 melanomas (Fig. 4C) and even weaker staining in 1/12 lung cancers, $1 / 10$ breast cancers and 2/10 colon cancers. The staining varied from nuclear to cytoplasmic.

There was up-regulation of TR1 and TR2 on tumor tissue compared with normal tissues (Fig. 4A, B). Their expression was strongest on melanoma where $10 / 13$ cases were positive with $50-90 \%$ of tumor cells stained positively. The staining was both nuclear and cytoplasmic, which mirrored the differential localization of these receptors on melanoma cell lines shown previously using confocal microscopy [22]. There was also a marked increase in TR1 (Fig. 4D) and TR2 expression on the epithelial cells of the gut. Here $9 / 10$ colon tumors were positive for these receptors, with $\sim 50 \%$ of tumor cells stained, although in 


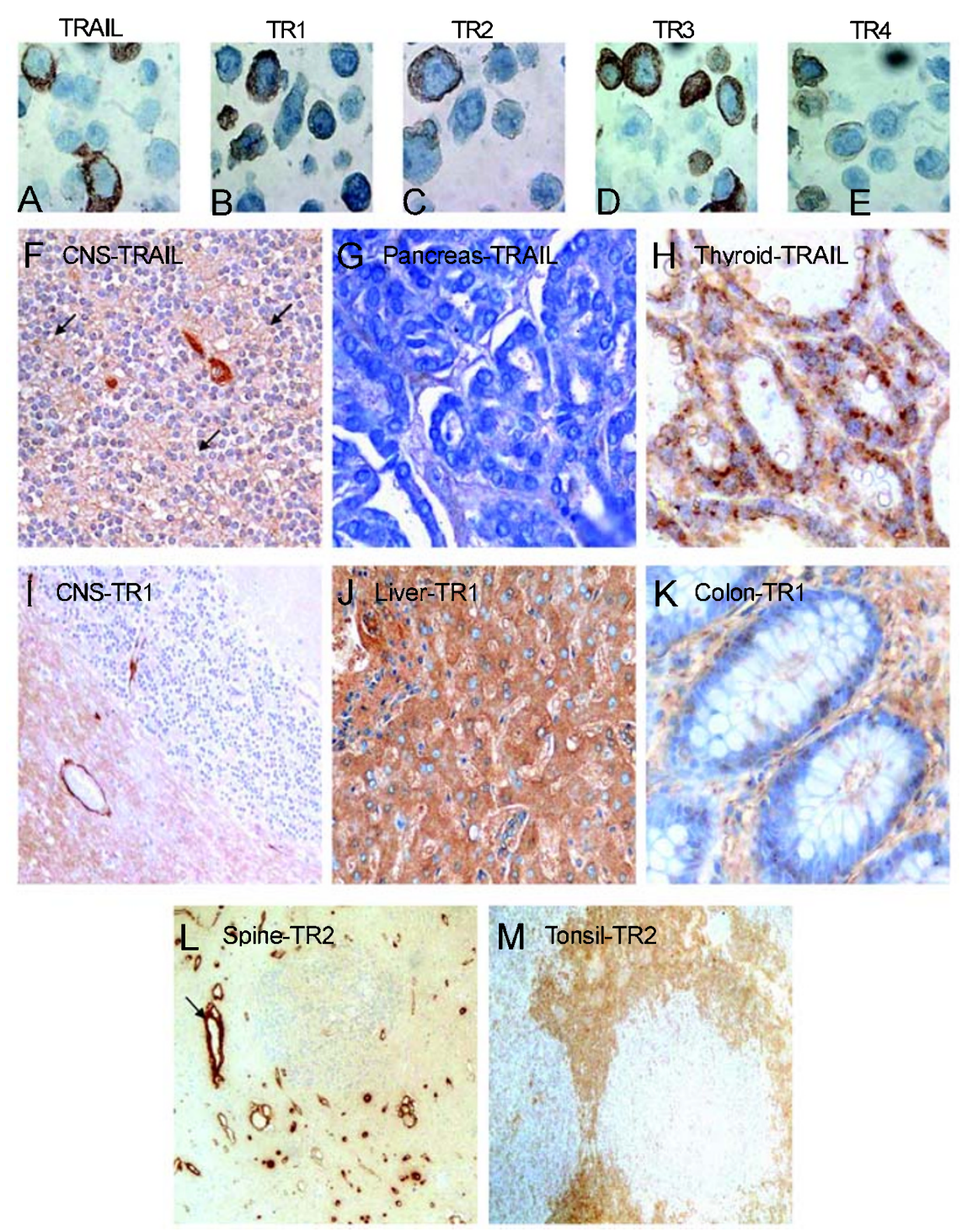

Fig. 3 Immunostaining for TRAIL and TRAIL Receptors. (A-E) 293T transfected cytospins were fixed in formalin (FFPE). Cells were transfected with the indicated cDNA and stained with the cognate mAb (TR3 was stained with the cross-reacting mAb anti-TR3/4). (F-M) paraffin embedded sections stained with the indicated antibodies. Arrows in $(\mathbf{F})$ indicates the granule cells in the granular layer of the grey matter of the cerebellum, and the arrow in $(\mathbf{L})$ indicates vascular smooth muscle in the spinal cord.

some cases staining was patchy with areas showing little or no expression (Fig. 4D). The entire breast cancer range investigated were either weakly positive or completely negative for both TR1 (Fig. 4E) and TR2. TR1 and TR2 expression was also increased in lung tumors (Fig. 4F).

Much work on TRAIL receptor expression and signaling has been performed on lymphocyte tumor cell lines. Many of these cell lines express high levels of TRAIL receptors, particularly TR2, and many also express TR1 (Fig. 1C) [23]. We were therefore surprised to find little or no expression of TRAIL receptors on tumors of lymphoid origin (Fig. 4G).

\section{DISCUSSION}

Much of the research into TRAIL and its receptors have been driven by its anti-tumorigenic properties, yet the true physiological role of TRAIL remains unanswered. Despite of being a potent inducer of apoptosis in tumor cells, most normal cells are resistant to TRAIL and it has been postulated that TRAIL has a crucial role in immune surveillance. TRAIL can be up-regulated on NK cells in response to IFN $\gamma$ and was shown to substantially contribute to tumor surveillance mediated by NK cells [24-26]. Moreover, TRAIL may also be involved in the anti-tumor effect mediated by cytokines such as IL-12 and IL-15 [24, 26, 
Tab. 2 The expression of TRAIL and receptors in tumours.

\begin{tabular}{lcclll}
\hline Tumor & Number & TRAIL & TRAIL-R1 & TRAIL-R2 & TRAIL-R3/4 \\
\hline Breast cancer & 10 & - & $+(5 / 10)$ & $+(6 / 10)$ & $\pm(1 / 10)$ \\
Melanoma & 13 & - & $+++(10 / 13)$ & $++++(11 / 13)$ & $\pm(5 / 13)$ \\
Lung cancer & 12 & - & $+++(10 / 12)$ & $+++(10 / 12)$ & $\pm(10 / 12)$ \\
Lymphoma & 12 & - & \pm & \pm & - \\
Gut cancer & 10 & - & $++(8 / 10)$ & $++(8 / 10)$ & $\pm(10 / 12)$ \\
\hline
\end{tabular}

Staining intensity was assessed for both tissue and cellular distribution. A semi-quantitative system was used: - negative; \pm equivocal; + weak; ++ moderate; +++ strong and ++++ very strong staining. The column designated "Number" gives the number of samples examined for each tumor type.
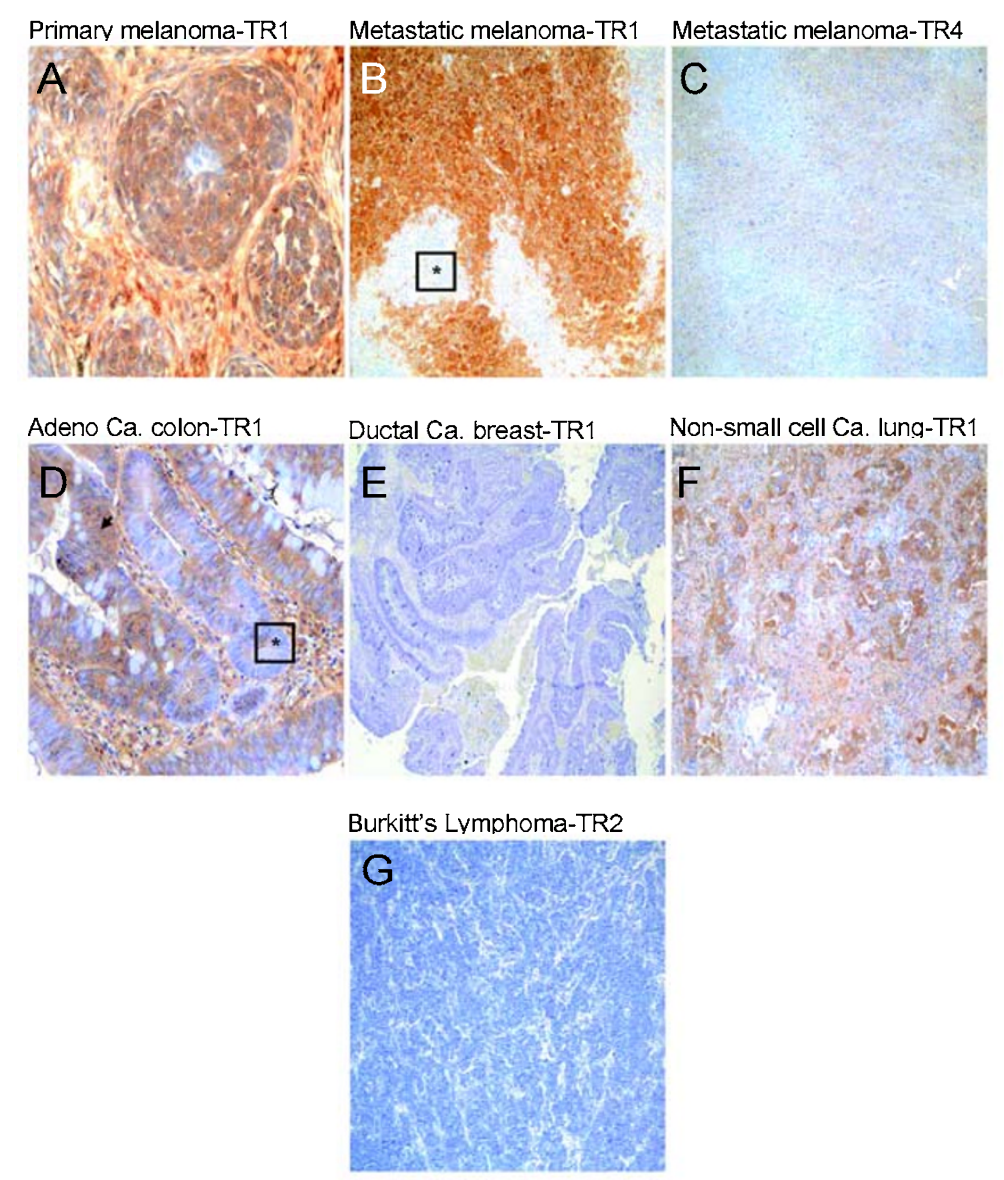

Fig. 4 Immunostaining for TRAIL and TRAILreceptors in malignant tissues. Paraffin embedded sections were stained with the indicated antibodies. The star in panel (B) marks the area of necrosis infiltrated by pyknotic neutrophils in a regressing melanoma lesion; the star and arrow in panel (D) mark one gland whose cells are either negative or strongly positive for TR1.

27].

In this study we report the production of reliable monoclonal antibodies against TRAIL and its receptors for routine use on pathological specimens. These have allowed us to study the expression of these proteins in a variety of normal tissues. As suggested from previous Northern blotting analyses, TR1 and TR2 is widely expressed, particularly high in hepatocytes $[3,4,6,28]$, and their sensitivity to TRAIL in vitro has generated much debate regarding its potential toxicity in therapeutic use [29]. TRAIL is now thought to play a crucial role in hepatic cell death and inflammation [30], although there has been some suggestion that this sensitivity may be related to the form of TRAIL administered [29, 31-35]. However, these 
preliminary studies must be treated with caution since a variety of other factors such as concomitant chemotherapy, pre-existing liver disease or conceivably the presence of multiple hepatic metastases, may predispose normal hepatocytes to TRAIL cytotoxicity. Hepatocytes also express high levels of Fas and were found to be sensitive to both FasL and anti-Fas monoclonal antibody [36, 37].

The decoy receptors, TR3 and TR4, were found to be expressed at low levels in a subset of tissues. Although the decoy receptors can be shown to inhibit TRAIL mediated apoptosis in a variety of model systems, studies of tumor cell lines have given mixed results. Some cells expressing decoys were sensitive to TRAIL, and others lacking decoys were resistant $[38,39]$. The simple explanation that differential expression of the TRAIL receptors might confer protection was in doubt and despite extensive research there is still no evidence for such 'decoy' activity within a physiological setting. It will be interesting to see future work regarding the true role of these receptors.

Surprisingly, we also found that TRAIL was expressed at relatively high levels in the CNS. This conflicts with previous work showing a lack of TRAIL in the CNS, despite widespread expression of all four of the membranebound receptors [40]. However, TRAIL-mediated cell death has been shown to follow ischemic damage in neurons, which would imply the expression of TRAIL in these cells [41]. TRAIL was also highly expressed in the thyroid. The sensitivity of thymocytes to TRAIL was previously reported by our group [42], although the role of TRAIL in negative selection has been a subject of some controversy and conflicting results [13, 42-44].

Much of the information on the expression and cytotoxicity of TRAIL has come from in vitro studies using tumor cell lines and so it will be useful to gain a clearer understanding of the expression of the TRAIL receptors on a variety of tumors [45]. Our preliminary results on a limited number of samples show that in many cases the expression of the death receptors, TR1 and TR2 have been up-regulated in tumor cells. However, in some common tumors such as breast and lymphoma, the expression is rather low, and in others their expression can only be found in a subset of the malignant cells. Despite this, it appears that tumor cells can be rendered sensitive to TRAIL using combination therapy with pre-existing anti-cancer drugs [46-50]. It was reported that the expression of TRAIL receptors could be induced by DNA damage under the regulation of p53 [51-53].

It will be important to see if such in vitro models of TRAIL sensitivity can be translated to tumors in vivo. One previous study examined the sensitivity of fresh melanoma samples to TRAIL [54]; the results were disappointing with few of the tumors being sensitive, despite the fact that 10 /
13 melanoma samples expressed TR1 and TR2. The suggested role of TRAIL in tumor surveillance makes it possible that tumors may actively down-regulate TR 1 and 2 expression or up-regulate intracellular regulators of apoptosis, such as the caspase inhibitor cFLIP [46, 54, 55]. It will be interesting to examine the sensitivity of fresh ex vivo tumor samples and compare primary and secondary tumor samples, with possible prognostic significance of TRAIL expression. This panel of antibodies will allow rapid characterisation of TRAIL receptor expression on biopsy material in order to identify patients most likely to benefit from therapy targeted to the TRAIL/TRAIL receptor axis.

\section{ACKNOWLEDGEMENTS}

Raymond A DANIELS is funded by a British Commonwealth Scholarship; Gavin R SCREATON, Xiao Ning XU, Juthathip MONGKOLSAPAYA, Fiona C KIMBERLEY and Paul CH'EN are funded by the Medical Research Council; Bo Quan JIN and Xue Song LIU are funded by the National Natural Science Foundation of China; Francesco PEZZELLA and Helen TURLEY are funded by Cancer Research, UK.

Received, Feb 5, 2005

Revised, Mar 29, 2005

Accepted, Mar 31, 2005

\section{REFERENCES}

1 Pitti RM, Marsters SA, Ruppert S, et al. Induction of apoptosis by Apo-2 ligand, a new member of the tumor necrosis factor cytokine family. J Biol Chem 1996; 271:12687-90.

2 Wiley SR, Schooley K, Smolak PJ, et al. Identification and characterization of a new member of the TNF family that induces apoptosis. Immunity 1995; 3:673-82.

3 Pan G, O'Rourke K, Chinnaiyan AM, et al. The receptor for the cytotoxic ligand TRAIL. Science 1997; 276:111-3.

4 Pan G, Ni J, Wei YF, et al. An antagonist decoy receptor and a death domain-containing receptor for TRAIL. Science 1997; 277: 815-8.

5 Walczak H, Degli-Esposti MA, Johnson RS, et al. TRAIL-R2: A novel apoptosis-mediating receptor for TRAIL. EMBO J 1997; 16:5386-97.

6 Screaton GR, Mongkolsapaya J, Xu XN, et al. TRICK2, a new alternatively spliced receptor that transduces the cytotoxic signal from TRAIL. Curr Biol 1997; 7:693-6.

7 Degli-Esposti MA, Smolak PJ, Walczak H, et al. Cloning and characterization of TRAIL-R3, a novel member of the emerging TRAIL receptor family. J Exp Med 1997; 186:1165-70.

8 Degli-Esposti MA, Dougall WC, Smolak PJ, et al. The novel

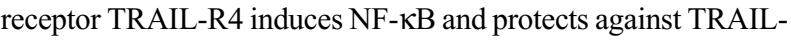
mediated apoptosis, yet retains an incomplete death domain. Immunity 1997; 7:813-20.

9 Marsters SA, Sheridan JP, Pitti RM, et al. A novel receptor for Apo21/TRAIL contains a truncated death domain. Curr Biol 1997; 
7:1003-6.

10 Emery JG, McDonnell P, Burke MB, et al. Osteoprotegerin is a receptor for the cytotoxic ligand TRAIL. J Biol Chem 1998; 273:14363-7.

11 Simonet WS, Lacey DL, Dunstan CR, et al. Osteoprotegerin: A novel secreted protein involved in the regulation of bone density. Cell 1997; 89:309-19.

12 Kong YY, Yoshida H, Sarosi I, et al. Opgl is a key regulator of osteoclastogenesis, lymphocyte development and lymph-node organogenesis. Nature 1999; 397:315-23.

13 Sedger LM, Glaccum MB, Schuh JC, et al. Characterization of the in vivo function of TNF- $\alpha$-related apoptosis-inducing ligand, TRAIL/apo21, using TRAIL/Apo21 gene-deficient mice. Eur J Immunol 2002; 32:2246-54.

14 Walczak H, Miller RE, Ariail K, et al. Tumoricidal activity of tumor necrosis factor-related apoptosis- inducing ligand in vivo. Nat Med 1999; 5:157-63.

15 Ichikawa K, Liu W, Zhao L, et al. Tumoricidal activity of a novel anti-human DR5 monoclonal antibody without hepatocyte cytotoxicity. Nat Med 2001; 7:954-60.

16 Chuntharapai A, Dodge K, Grimmer K, et al. Isotype-dependent inhibition of tumor growth in vivo by monoclonal antibodies to death receptor $4 \mathrm{~J}$ Immunol 2001; 166:4891-8.

17 Mongkolsapaya J, Grimes JM, Chen N, et al. Structure of the TRAIL-DR 5 complex reveals mechanisms conferring specificity in apoptotic initiation. Nat Struct Biol 1999; 6:1048-53.

18 Turley H, Jones M, Erber W, et al. Vs38: A new monoclonal antibody for detecting plasma cell differentiation in routine sections. J Clin Pathol 1994; 47:418-22.

19 Bretz JD, Rymaszewski M, Arscott PL, et al. TRAIL death pathway expression and induction in thyroid follicular cells. J Biol Chem 1999; 274:23627-32.

20 Bretz JD, Baker JR Jr. Apoptosis and autoimmune thyroid disease: Following a TRAIL to thyroid destruction? Clin Endocrinol (Oxf) 2001; 55:1-11.

21 Strater J, Walczak H, Pukrop T, et al. TRAIL and its receptors in the colonic epithelium: A putative role in the defense of viral infections. Gastroenterology 2002; 122:659-66.

22 Zhang XD, Franco AV, Nguyen T, et al. Differential localization and regulation of death and decoy receptors for TNF-related apoptosis-inducing ligand (TRAIL) in human melanoma cells. J Immunol 2000; 164:3961-70.

23 Mouzakiti A, Packham G. Regulation of tumor necrosis factorrelated apoptosis-inducing ligand (TRAIL)-induced apoptosis in burkitt's lymphoma cell lines. Br J Haematol 2003; 122:61-9.

24 Takeda K, Smyth MJ, Cretney E, et al. Critical role for tumor necrosis factor-related apoptosis-inducing ligand in immune surveillance against tumor development. J Exp Med 2002; 195:161-9.

25 Smyth MJ, Cretney E, Takeda K, et al. Tumor necrosis factorrelated apoptosis-inducing ligand (TRAIL) contributes to interferon $\gamma$-dependent natural killer cell protection from tumor metastasis. J Exp Med 2001; 193:661-70.

26 Takeda K, Smyth MJ, Cretney E, et al. Involvement of tumor necrosis factor-related apoptosis-inducing ligand in NK cellmediated and IFN- $\gamma$-dependent suppression of subcutaneous tumor growth. Cell Immunol 2001; 214:194-200.

27 Frank S, Kohler U, Schackert G, Schackert HK. Expression of TRAIL and its receptors in human brain tumors. Biochem Biophys Res Commun 1999; 257:454-9.
28 Sheridan JP, Marsters SA, Pitti RM, et al. Control of TRAILinduced apoptosis by a family of signaling and decoy receptors. Science 1997; 277:818-21.

29 Jo M, Kim TH, Seol DW, et al. Apoptosis induced in normal human hepatocytes by tumor necrosis factor- related apoptosisinducing ligand. Nat Med 2000; 6:564-7.

30 Zheng SJ, Wang P, Tsabary G, Chen YH. Critical roles of TRAIL in hepatic cell death and hepatic inflammation. J Clin Invest 2004; 113:58-64.

31 Lawrence D, Shahrokh Z, Marsters S, et al. Differential hepatocyte toxicity of recombinant Apo21/ TRAIL versions. Nat Med 2001; 7:383-5.

32 Lin T, Gu J, Zhang L, et al. Targeted expression of green fluorescent protein/tumor necrosis factor-related apoptosis-inducing ligand fusion protein from human telomerase reverse transcriptase promoter elicits antitumor activity without toxic effects on primary human hepatocytes. Cancer Res 2002; 62:3620-5.

33 Yamashita Y, Shimada M, Tanaka S, et al. Electroporation-mediated tumor necrosis factor-related apoptosis-inducing ligand (TRAIL)/Apo21 gene therapy for hepatocellular carcinoma. Hum Gene Ther 2002; 13:275-86.

34 Kagawa $\mathrm{S}, \mathrm{He} \mathrm{C}, \mathrm{Gu}$ J, et al. Antitumor activity and bystander effects of the tumor necrosis factor-related apoptosis-inducing ligand (TRAIL) gene. Cancer Res 2001; 61:3330-8.

35 Mundt B, Kuhnel F, Zender L, et al. Involvement of TRAIL and its receptors in viral hepatitis. Faseb J 2003; 17:94-6.

36 Galle PR, Hofmann WJ, Walczak H, et al. Involvement of the CD95 (Apo-1/Fas) receptor and ligand in liver damage. J Exp Med 1995; 182:1223-30.

37 Ogasawara J, Watanabe-Fukunaga R, Adachi M, et al. Lethal effect of the anti-fas antibody in mice. Nature 1993; 364:806-9.

38 Zhang XD, Franco A, Myers K, et al. Relation of TNF-related apoptosis-inducing ligand (TRAIL) receptor and flice-inhibitory protein expression to TRAIL-induced apoptosis of melanoma. Cancer Res 1999; 59:2747-53.

39 Griffith TS, Rauch CT, Smolak PJ, et al. Functional analysis of TRAIL receptors using monoclonal antibodies. J Immunol 1999; 162:2597-605.

40 Dorr J, Bechmann I, Waiczies S, et al. Lack of tumor necrosis factor-related apoptosis-inducing ligand but presence of its receptors in the human brain. J Neurosci 2002; 22:RC209.

41 Martin-Villalba A, Herr I, Jeremias I, et al. Cd95 ligand (Fas-1/ Apo-11) and tumor necrosis factor-related apoptosis-inducing ligand mediate ischemia-induced apoptosis in neurons. J Neurosci 1999; 19:3809-17.

42 Simon AK, Williams O, Mongkolsapaya J, et al. Tumor necrosis factor-related apoptosis-inducing ligand in t cell development: Sensitivity of human thymocytes. Proc Natl Acad Sci U S A 2001; 98:5158-63.

43 Lamhamedi-Cherradi SE, Zheng SJ, Maguschak KA, et al. Defective thymocyte apoptosis and accelerated autoimmune diseases in TRAIL ${ }^{-/}$mice. Nat Immunol 2003; 4:255-60.

44 Cretney E, Uldrich AP, Berzins SP, et al. Normal thymocyte negative selection in TRAIL-deficient mice J Exp Med 2003; 198:491-6.

45 Griffith TS, Lynch DH. TRAIL: A molecule with multiple receptors and control mechanisms. Curr Opin Immunol 1998; 10:55963.

46 Ganten TM, Haas TL, Sykora J, et al. Enhanced caspase-8 re- 
cruitment to and activation at the disc is critical for sensitisation of human hepatocellular carcinoma cells to TRAIL-induced apoptosis by chemotherapeutic drugs. Cell Death Differ 2004; 11 Suppl 1:S86-96

47 Nimmanapalli R, Perkins CL, Orlando M, et al. Pretreatment with paclitaxel enhances Apo-2 ligand/tumor necrosis factorrelated apoptosis-inducing ligand-induced apoptosis of prostate cancer cells by inducing death receptors 4 and 5 protein levels. Cancer Res 2001; 61:759-63.

48 Singh TR, Shankar S, Chen X, et al. Synergistic interactions of chemotherapeutic drugs and tumor necrosis factor-related apoptosis-inducing ligand/Apo-2 ligand on apoptosis and on regression of breast carcinoma in vivo. Cancer Res 2003; 63:5390400.

49 Kelly MM, Hoel BD, Voelkel-Johnson C. Doxorubicin pretreatment sensitizes prostate cancer cell lines to TRAIL induced apoptosis which correlates with the loss of c-FLIP expression. Cancer Biol Ther 2002; 1:520-7.

50 Voelkel-Johnson C. An antibody against DR4 (TRAIL-R1) in combination with doxorubicin selectively kills malignant but not normal prostate cells. Cancer Biol Ther 2003; 2:283-90.

51 Takimoto R, El-Deiry WS. Wild-type p53 transactivates the killer/DR5 gene through an intronic sequence-specific DNA-binding site. Oncogene 2000; 19:1735-43.

$52 \mathrm{Wu}$ GS, Burns TF, McDonald ER 3rd, et al. Killer/DR5 is a DNA damage-inducible p53-regulated death receptor gene. Nat Genet 1997; 17:141-3.

53 Sheikh MS, Huang Y, Fernandez-Salas EA, et al. The antiapoptotic decoy receptor TRID/TRAIL-R3 is a p53-regulated DNA damageinducible gene that is overexpressed in primary tumors of the gastrointestinal tract. Oncogene 1999; 18:4153-9.

54 Nguyen T, Zhang XD, Hersey P. Relative resistance of fresh isolates of melanoma to tumor necrosis factor-related apoptosisinducing ligand (TRAIL)-induced apoptosis Clin Cancer Res 2001; 7 (3 Suppl):966s-73s.

55 Schneider P, Thome M, Burns K, et al. TRAIL receptors 1 (DR4) and 2 (DR5) signal FADD-dependent apoptosis and activate NF-אB. Immunity 1997; 7:831-6. 